\title{
Computer Use and Productivity Growth
}

\author{
Rubén Hernández-Murillo
}

$\mathrm{T}$ he application of computing technologies by U.S. firms has exploded in recent years. Between 1990 and 2000, the average annual growth rate of real investment in computer capital was about 33 percent. Ever-declining prices of computer equipment, in quality-adjusted terms, allow firms to pursue more powerful and sophisticated applications of computers and improve the efficiency of basic business functions, such as supply-chain management. Although the rapid growth of computer investment contributes directly to business investment spending, economists have for a long time wondered how computer investment affects productivity. The impact could be substantial if the use of computers facilitates a broad collection of complementary innovations within firms. Until recently, however, the connection between computer use and business productivity growth has been unclear. ${ }^{1}$

Reexamining standard growth-accounting techniques, similar to those used in this publication, economists have identified in recent studies that computers do have potentially large effects on productivity growth-particularly in the long run, when computing technologies interact fully with a firm's business practices. Because the benefits of computers are largely oriented toward intangible aspects of business activity, the impact of computer use may not be reflected in aggregate statistics. Indeed, investment in these technologies may have little direct impact on a firm's productivity; only when these technologies are combined with organizational aspects over time do the contributions of computer investment become apparent. One example is Wal-Mart's proprietary software that processes a large array of computer-collected data to determine specific goods to stock at specific stores at specific times of year, as well as their prices.

Brynjolfsson and Hitt (2003) estimate the impact of computers on productivity by using firm-level data to reduce measurement problems of outputs and inputs that exist in industry-level data. ${ }^{2}$ They find that computer use accounts for a substantial share of total factor productivity (TFP) and output growth. ${ }^{3}$ They also find that computer investment has its maximal impact on productivity after about seven years. They estimate that, between 1987 and 1994, about 0.25 to 0.50 percentage points of TFP growth at the firm level was generated by the use of computer capital, which grew by about 25 percent per year.

Although many studies focus on TFP growth, computers also contribute to labor productivity growth by increasing the stock of capital per worker. As seen in the chart, computer investment accelerated early in the 1990s, long before the "new economy" productivity acceleration took place. If the firm-level results are translated to the overall economy, the gains in TFP growth from the 1995-99 flurry of computer investment growth (which exceeded 40 percent per year) should peak around 2006. Hence, there is cause for optimism regarding productivity over the next few years, as the evidence suggests that the benefits from computer use persist long after firms have undertaken the investment.

\footnotetext{
${ }^{1}$ Robert Solow noted a few years back that the computer age is seen everywhere except in productivity data. See Michael R. Pakko: "Accounting for Computers," Federal Reserve Bank of St. Louis, National Economic Trends, May 2001.

${ }^{2}$ See "Computing Productivity: Firm-Level Evidence," Review of Economics and Statistics, November 2003, 85(4), pp. 793-808.

${ }^{3}$ TFP growth, often called the Solow residual, captures the difference in output growth that cannot be explained by capital and labor input growth.
}

\section{Productivity and Computer Investment Growth 1990-2002}

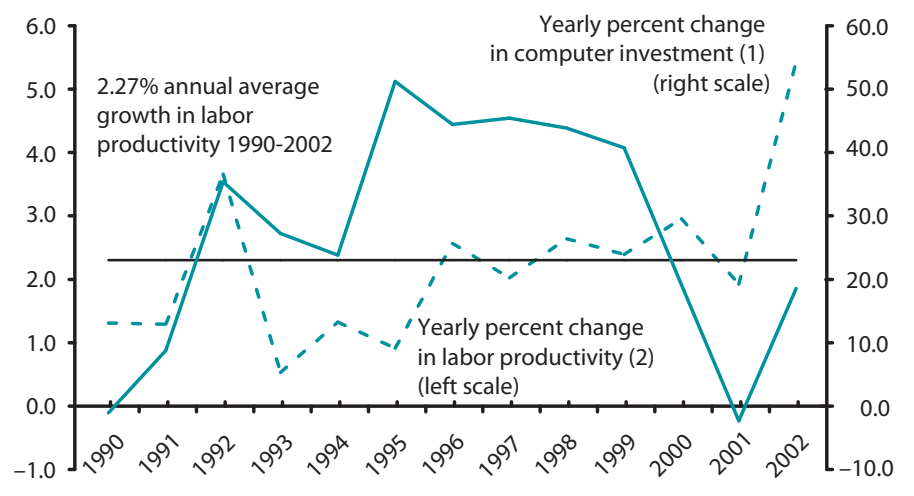

NOTE: (1) Real private fixed investment in new computers and peripheral equipment (National Income and Product Accounts). (2) Output per hour for all persons in the nonfarm business sector (U.S. Department of Labor). 